\title{
Foodborne intestinal protozoan infection and associated factors among patients with watery diarrhea in Northern Ethiopia; a cross-sectional study
}

\author{
Birhane Berhe ${ }^{1}$, Gessessew Bugssa², Sena Bayisa ${ }^{2}$ and Megbaru Alemu ${ }^{3,4^{*}}$
}

\begin{abstract}
Background: Intestinal protozoa are parasites transmitted by consumption of contaminated water and food and mainly affect children and elder people and cause considerable health problems. They are the leading causes of outpatient morbidity due to diarrhea in the developing countries. So, assessing water and food source of diarrheal patients and identifying the main associated factors for transmission of protozoan parasitic infections help for effective control measures of protozoan infections. Hence, the current study was aimed at determining the prevalence of foodborne intestinal protozoa infections and associated factors among diarrheic patients in North Ethiopia.

Methods: A health facility based cross-sectional study was conducted among 223 patients with watery diarrhea in four selected government health facilities in North Ethiopia from November 2016-June 2017. A structured questionnaire was used to collect data on socio-demography of study participants and factors associated with foodborne protozoa infections. The diarrheic stool samples were collected, transported, and processed using direct wet mount, formal-ether concentration and modified ZiehINeelson staining methods. The data were analyzed using SPSS version 21 and descriptive statistics, bi-variate, and multivariate logistic regressions were computed. $P$-value $<0.05$ at $95 \%$ confidence interval was considered statistically significant.
\end{abstract}

Results: The overall prevalence of foodborne protozoa infection was 101 (45.3\%). The predominant protozoa species identified was Entamoeba histolytica/dispar 55 (24.7\%), followed by Giardia intestinalis 25 (11.2\%) and Cryptosporidium species 5 (2.2\%). The highest proportion of protozoa infection was observed among males (23.3\%) and the age group 15-24 years (13.5\%). Statistically significant associations were observed between foodborne protozoan infection and not using any type of recipe to decontaminate salads and fruits ( $A O R=2.64,95 \mathrm{Cl}: 1.34-5.19, P=0.005)$ and using vinegar as a decontaminant ( $A O R=2.83,95 \mathrm{Cl}: 1.24-6.48, P=0.014)$. Eating out (meals at a restaurant) on the other hand was found to be protective for foodborne protozoan infection ( $A O R=0.43,95 \mathrm{Cl}: 0.23-0.78, P=0.006$ ).

Conclusion: Our study revealed that foodborne protozoa infections are of public health significance in the study area. Vinegar, which is frequently used as a recipe for decontaminating salads and fruits, is inversely related to foodborne protozoa parasite infection .

Keywords: Food borne, Protozoa, Diarrheal, Ethiopia

\footnotetext{
* Correspondence: mgbeyney@gmail.com

${ }^{3}$ Department of Medical Microbiology, Immunology and Parasitology, Bahir

Dar University, Mekelle, Ethiopia

${ }^{4}$ Department of Microbiology, Immunology and Parasitology, Bahir Dar

University, PO Box 79, Bahir Dar, Ethiopia

Full list of author information is available at the end of the article
} 


\section{Background}

Intestinal protozoa are a diverse group of unicellular organisms inhabiting the intestinal tract of humans [1]. Infections usually occur through ingestion of cysts/oocysts contaminating food or drinking water [2, 3]. Infection with intestinal protozoa parasites have worldwide distribution and particularly common in tropics and sub-tropics areas of the world with millions of cases of diarrhea occurring in each year. There are a number of intestinal protozoa that cause diarrhea, but Entamoeba histolytica, Giardia intestinalis and Cryptosporidium species are the most important causes of diarrhea [4-6].

Giardiasis is the most frequently reported intestinal protozoan disease in the world, with about 280 million symptomatic cases and 2.5 million annual deaths each year [7]. An estimated 748,000 cryptosporidiosis cases also occur annually, though less than $2 \%$ are reported due to poor sensitivity of the routine direct wet mount microscopy. Hospitalizations resulting from cryptosporidiosis cost an estimated 45.8 million dollars per year [8]. Amoebiasis is also a common cause of intestinal protozoan infections throughout the tropics.

In Ethiopia, morbidity and mortality due to diarrheal diseases remain to be the main public health problem that needs attention in the country. The lack of safe drinking water, poor environmental sanitation, and poor socioeconomic status are responsible for more than 800 million cases and 4.5 million deaths associated with diarrheal diseases occurring every year $[9,10]$. Malnutrition, anemia, growth restrictions, cognitive delays, irritability and increased susceptibility to other infections are some of the consequence of diarrhea morbidities [11, 12].

Several studies have addressed the epidemiology of intestinal parasites mainly in apparently healthy school children in Ethiopia [13-19], yet there exists paucity of data on the diarrheal causes of food borne intestinal protozoan parasites in the country in general and North Ethiopia in particular. In addition, the pattern of intestinal parasitism in a population with diverse groups of people was not illustrated. Furthermore, most previous studies have not employed the modified Ziehl Neelson staining method for the diagnosis of opportunistic intestinal coccidian parasites and consequently, they were under-reported so far. Hence, we planned to determine the magnitude of food borne protozoa species associated with diarrhea among patients with watery diarrhea in North Ethiopia.

\section{Methods}

\section{Study design, period and area}

This cross-sectional study was conducted in selected government health facilities in Mekelle City from November 2016 to June 2017. Mekelle city is located $780 \mathrm{~km}$ north of Addis Ababa at a latitude and longitude of $13^{\circ} 29^{\prime} \mathrm{N} 39^{\circ} 28^{\prime} \mathrm{E}$ with an elevation of $2084 \mathrm{~m}$ above sea level. The average annual temperature is $18.0{ }^{\circ} \mathrm{C}$. Based on the 2007 census conducted by the Central Statistical Agency of Ethiopia (CSA), the city has a total population of $215,914 \quad(104,925$ men and 110,989 women). The main source of water is ground water from 19 boreholes that range from 32 to $250 \mathrm{~m}$ deep. There were 13 governmental health facilities (2 hospitals and 11 health centers) in the city [20].

\section{Study participants}

The study participants for this particular research work were volunteer diarrheic outpatients who were requested for stool examination in the health facilities during the study period. The patients visited the health facilities with a chief complaint of diarrhea. Those patients who took medication for intestinal parasites within 1 month prior to the study were excluded. Moreover, patients who were severely ill and were unable to give stool sample were excluded from the study. The study participants were selected by a non-probability convenient sampling.

\section{Study size}

A sample size of 226 was determined using single population proportion statistical formula by the following assumptions: $95 \%$ level of confidence, 5\% margin of error and $\mathrm{P}$ (proportion) of 0.16 [21], and non-response rate of $10 \%$. From a total of 13 health institutions of Mekelle City, one hospital and three health centers were selected randomly. Accordingly, Mekelle hospital, Mekelle health center, Semien health center and Adishimdihun health center were included in this study. The 226 study subjects were proportionally allocated to the health facilities based on the size of patient flow within 3 months prior to our study.

\section{Data collection \\ Questionnaire}

Data on demographic characteristics of study participants and associated factors of protozoan infections were collected using structured and pre-tested questionnaire. The questionnaire was developed based on previous research works and pre-tested in Ayder referral hospital. The face-to-face interview was conducted by trained data collectors.

\section{Stool examination}

Labeled stool containers with tight covers bearing serial numbers of the subjects were supplied for the study participants. Fecal specimens were processed by wet mount, Formol-ether concentration (FEC) and modified Ziehl Neelson staining methods. 


\section{Wet mount technique}

Fresh stool samples (approximately $2 \mathrm{mg}$ of stool) were put on a slide with the wooden applicator and emulsified with a drop of physiological saline $(0.85 \%)$. The preparation was then covered with a cover slide and examined at $10 \times$ and $40 \times$ microscopic objectives [6].

\section{Formol ether concentration technique}

Approximately $0.5 \mathrm{~g}$ of feces was mixed with $10 \mathrm{ml}$ of normal saline and the mixed stool was strained via gauze into a funnel. The strained contents were collected in a centrifuge tube. About $2.5 \mathrm{ml}$ of $10 \%$ formaldehyde and $1 \mathrm{ml}$ of ether were then added and centrifuged at $1000 \mathrm{~g}$ for $3 \mathrm{~min}$. The supernatant was removed and a drop of the sediment was covered with cover glass for a microscopic investigation [6].

\section{Modified Ziehl-Neelsen technique}

Thin fecal smears were prepared from fresh fecal specimens and air dried. Following fixation with methanol for $5 \mathrm{~min}$, the primary stain (carbon fuchsin) was applied for $10 \mathrm{~min}$. The smear was washed and decolorized with $1 \%$ acid alcohol. The counter stain $(0.5 \%$ malachite green) was then applied for $30 \mathrm{~min}$. The smear was washed off, dried and examined accordingly [6].

\section{Quality control}

The Questionnaire was pre-tested before actual data collection. Diarrheic specimens were processed within 15 min of collection to demonstrate the motile protozoa trophozoites. The collected data were checked for consistency and accuracy on a daily basis. All the laboratory procedures were conducted as per the Standard Operating Procedures (SOPs).

\section{Statistical analysis}

Data were entered and analyzed using statistical software package (IBM Comp. released2011. IBM SPSS statistics for windows, version 20 Armonk, NY: IBM comp). Data were summarized using descriptive statistics. Bi-variate and multi-variate regression tests were employed to measure the strength of association between dependent and independent variables. Variables with $P<0.2$ in the bi-variate logistic regression were transferred to multivariate regression analysis and the AOR was computed to control potential confounders.. P-value less than 0.05 was considered statistical significant.

\section{Results}

\section{Demographic characteristics}

A total of 223 diarrheic outpatients were enrolled with a response rate of $98.7 \%$. Out of the total respondents, 124 (55.6\%) were males. The median age of study participants was 21 years, ranging $1-80$ years (Table 1).
Table 1 Demographic characteristics of the study participants in selected government health facilities of Mekelle City, North Ethiopia, 2017

\begin{tabular}{lll}
\hline Variables & Frequency & Percent (\%) \\
\hline Sex & 124 & 55.6 \\
Male & 99 & 44.4 \\
Female & & \\
Age (Yrs) & 36 & 16.1 \\
$<5$ & 46 & 20.6 \\
5-14 & 55 & 24.7 \\
15-24 & 44 & 19.7 \\
$25-34$ & 16 & 7.2 \\
$35-44$ & 26 & 11.7 \\
$>=45$ & & \\
Occupation & 23 & 10.3 \\
Civil servant & 37 & 16.6 \\
Self-employed & 4 & 1.8 \\
Farmer & 159 & 71.3 \\
Unemployed & & 13 \\
Educational level & 38 & 17.2 \\
Illiterate & 47 & 21.1 \\
Read and write & 34 & 13 \\
Primary school & 75 & \\
High school & & \\
College and above & & \\
\hline
\end{tabular}

Majority of the study participants were in the age group of $15-24$ years $(24.7 \%)$, high school graduates $(33.6 \%)$ and unemployed (71.3\%).

\section{Prevalence of food borne intestinal protozoa}

The overall prevalence of intestinal protozoa infection was $45.3 \%(101 / 223)$ and higher infection rates were recorded for males (23.3\%) and the age group 15-24 years (13.5\%) (Table 2). E. histolytica/dispar, 55 (24.7\%) was the predominant parasite followed by G. intestinalis, 25 (11.2\%) and Cryptosporidium species, 5 (2.2\%). The rate of double infection accounted for $6.7 \%(15 / 223)$, the predominant co-existent infection being $E$. histolytica/dispar and $G$. intestinalis (4.9\%) (Table 2).

The prevalence of G. intestinalis and Cryptosporidium species among males was $6.7 \%$ and $1.8 \%$, respectively. Higher prevalence of $G$. intestinalis and E. histolytica/ dispar was found in the age group 15-24 years, 3.6\% and $6.7 \%$, respectively (Table 2 ).

Factors associated with food borne protozoan infections The prevalence of food borne protozoa infection was higher among those who had no regular hand washing habit before a meal, those whose house hold water was 
Table 2 Distribution of food borne protozoa by sex and age among diarrheic patients in selected government health facilities of Mekelle City, NorthEthiopia, 2017

\begin{tabular}{|c|c|c|c|c|c|c|c|c|}
\hline \multirow[t]{2}{*}{ Parasite species } & \multicolumn{2}{|l|}{ Gender } & \multicolumn{5}{|c|}{ Age (Yrs) } & \multirow[b]{2}{*}{$\begin{array}{l}\geq 45 \\
\text { n (\%) }\end{array}$} \\
\hline & $\begin{array}{l}\text { Male } \\
\text { n (\%) }\end{array}$ & $\begin{array}{l}\text { Female } \\
\mathrm{n}(\%)\end{array}$ & $\begin{array}{l}<5 \\
\text { n (\%) }\end{array}$ & $\begin{array}{l}5-14 \\
n(\%)\end{array}$ & $15-24$ n (\%) & $\begin{array}{l}25-34 \\
n(\%)\end{array}$ & $\begin{array}{l}35-44 \\
n(\%)\end{array}$ & \\
\hline \multicolumn{9}{|l|}{ Single infection } \\
\hline G. intestinalis & $15(6.7)$ & $10(4.5)$ & $5(2.2)$ & $6(2.7)$ & $8(3.6)$ & $3(1.3)$ & $1(0.4)$ & $2(0.9)$ \\
\hline E. histolytica & $28(12.5)$ & $27(12.2)$ & $10(4.5)$ & $12(5.4)$ & $15(6.7)$ & $8(3.6)$ & $5(2.2)$ & $5(2.2)$ \\
\hline Cryptosporidium spp & $4(1.8)$ & $1(0.4)$ & - & $2(0.9)$ & $2(0.9)$ & $1(0.4)$ & - & - \\
\hline \multicolumn{9}{|l|}{ Double infection } \\
\hline G. intestinalis + E. histolytica & $5(2.2)$ & $6(2.7)$ & - & $1(0.4)$ & $4(1.8)$ & $1(0.4)$ & $1(0.4)$ & $4(1.8)$ \\
\hline G. intestinalis + Cryptosporidium spp & $1(0.4)$ & - & - & - & - & $1(0.4)$ & - & - \\
\hline E. histolytica Cryptosporidium spp & $1(0.4)$ & $2(0.9)$ & - & - & $1(0.4)$ & $1(0.4)$ & - & - \\
\hline
\end{tabular}

sourced from rivers and those whose toilets were $<5 \mathrm{~m}$ from their kitchens. However, the difference was not statistically significant $(P>0.05)$. All variables with $P<0.2$ in the bi-variate logistic analysis were taken to multiple logistic regressions. In multivariate analysis, using vinegar as a decontaminant for vegetables and fruits $(\mathrm{AOR}=2.83,95 \%$ CI: $1.24-6.48, P=0.014)$ and not using any type of recipe as a decontaminant $(\mathrm{AOR}=2.64,95 \mathrm{CI}: 1.34-5.19, P=$ 0.005 ) were significant indicators of intestinal protozoan infection. 'Eating out' (eating at a restaurant) was significantly associated with a lower odds of intestinal protozoa infection $\quad(\mathrm{AOR}=0.43,95 \mathrm{CI}: \quad 0.23-0.78, \quad P=0.006)$ (Table 3).

\section{Discussion}

Intestinal protozoa are considered important emerging pathogens contributing to diarrheal disease outbreaks in developing nations where declining water quality is a persistent problem [22]. In our study, the overall prevalence of protozoan infection was $45.3 \%$. Our finding was higher than the study conducted in Southern Ethiopia 16.6\% [10], Southwestern Iran 32.2\% [23] and Western Iran 37.5\% [24]. However, it was lower than findings from South Africa 68\% [25] and Lebanon 85\% [26] among diarrheic patients. These inconsistencies might be due to differences in living standards of study participants, environmental sanitation, hand washing and hygiene practices of the populations and usage of latrine and waste disposal [10, 23]. The stool examination techniques utilized in different research works might also have contributed for such inconsistencies [23, 27-29].

E. histolytica/dispar with a prevalence of $24.7 \%$ was the predominant species among diarrheic patients in our study. This was higher than studies in Ethiopia; Jimma 5.6\% [15], Gondar 10.3\% [30], and elsewhere; Saudi Arabia 4.7\% [31], Malaysia 0.4\% [32], Italy 4.1\% [33] and Myanmar $6.2 \%$ [34]. The higher prevalence of E. histolytica/dispar in this study might be due to poor access to safe drinking water supplies which is testified by the fact that about half of the study participants used unprotected water for drinking and cooking in our study. Giardiasis accounted for $11.2 \%$ in our study which was higher than reports from Philippines 2\% [35], India 5\% [36] and China 6.8\% [37]. But it was lower than findings from Ethiopia 25.5\% [38], and South Africa 20.8\% [25].

In this study, the prevalence of Cryptosporidium species (2.2\%) was lower than reports from India 16.3\% [36] and China 13.49\% [37]. The observed difference could be due to absence of advanced molecular technique to detect Cryptosporidium species. The prevalence of Giardia intestinalis and Cryptosporidium species was higher in males than females. This was consistent with the study in Lebanon [26], Iraq [39], Nigeria [40], and Saudi Arabia [41]. This might be due to the fact that males have more exposure as they are frequently engaged in practices such as dealing with farm animals as zoonotic transmission could happen.

In the multi-variate analysis, study participants who did not use any type of recipe to decontaminate vegetables and fruits were 2.6 times at higher risk of acquiring foodborne intestinal protozoa infection. This might be due to the practice of growing of vegetables and fruits in gardens where night soils and untreated human feces is used as fertilizer as testified by our finding that more than $10 \%$ of the participants reported open defecation. In addition, long survival of protozoa cysts/oocysts in moist soils might be attributed to risk of infections. Similarly, the risk of protozoan infection was 2.8 times higher among those who used vinegar compared to those who use lemon as a recipe to clean fruits and vegetables. This might be an indication that the routinely used vinegar to decontaminate fruits and vegetables has poor killing effect to cysts of foodborne protozoa parasites. Reduced cysticidal activity of vinegar was documented at low temperatures in previous studies $[42,43]$. In addition, the giardiacidal activity of lemon juice was indicated in a previous study [43]. 
Table 3 Bi-variate and multi-variate logistic regression analysis of factors associated with foodborne protozoan infection among diarrheic patients in selected government health facilities of Mekelle City, North Ethiopia, 2017

\begin{tabular}{|c|c|c|c|c|c|c|}
\hline \multirow[t]{2}{*}{ Variables } & \multicolumn{2}{|c|}{ Parasite status } & \multirow[t]{2}{*}{ COR $(95 \% \mathrm{Cl})$} & \multirow[t]{2}{*}{$P$-value } & \multirow[t]{2}{*}{ AOR $(95 \% \mathrm{Cl})$} & \multirow[t]{2}{*}{$P$-value } \\
\hline & $\begin{array}{l}\text { Positive } \\
\mathrm{N}(\%)\end{array}$ & $\begin{array}{l}\text { Negative } \\
\mathrm{N}(\%)\end{array}$ & & & & \\
\hline \multicolumn{7}{|l|}{ Water treatment } \\
\hline No treatment & $39(45.9)$ & $46(54.1)$ & $0.9(0.5-1.6)$ & 0.68 & & \\
\hline Boiling/filtration & $14(35)$ & $26(65)$ & $0.6(0.26-1.2)$ & 0.14 & $0.8(0.34-1.8)$ & 0.8 \\
\hline Chemical treatment & $48(49)$ & $50(51)$ & 1 & & 1 & \\
\hline \multicolumn{7}{|c|}{ Water source for drinking and cooking } \\
\hline Protected water & $95(45.2)$ & $115(54.8)$ & 1 & & & \\
\hline Unprotected water & $6(46.2)$ & $7(53.8)$ & $1.04(0.34-3.12)$ & 0.95 & & \\
\hline \multicolumn{7}{|l|}{ Regular hand washing } \\
\hline Yes & $99(45)$ & $121(55)$ & 1 & & & \\
\hline No & $2(66.7)$ & $1(33.3)$ & $2.44(0.41-4.6)$ & 0.47 & & \\
\hline \multicolumn{7}{|c|}{ Feces disposal/defecation } \\
\hline Open defecation & $13(56.5)$ & $10(43.5)$ & $2.1(0.85-5.03)$ & 0.11 & $0.42(0.16-1.22$ & \\
\hline Pit latrine & $32(58.2)$ & $23(41.8)$ & $2.2(1.18-4.16)$ & 0.014 & $0.95(0.32-2.8)$ & 0.92 \\
\hline Flash latrine & $56(38.6)$ & $89(61.4)$ & 1 & & 1 & \\
\hline \multicolumn{7}{|c|}{ Distance of kitchen from toilet (meter) } \\
\hline $20-30$ & $17(42.5)$ & $23(57.5)$ & 1 & & & \\
\hline $10-20$ & $35(45.5)$ & $42(54.5)$ & $1.13(0.52-2.44)$ & 0.76 & & \\
\hline $5-10$ & $32(42.7)$ & $43(57.3)$ & $1.01(0.46-2.19)$ & 0.97 & & \\
\hline$<5$ & $17(54.8)$ & $14(45.2)$ & $1.62(0.64-4.23)$ & 0.3 & & \\
\hline \multicolumn{7}{|c|}{ Decontaminant used for vegetables and fruits } \\
\hline Lemon & $17(28.8)$ & $42(71.2)$ & 1 & & 1 & \\
\hline Vinegar & $24(54.5)$ & $20(45.5)$ & $3(1.31-6.72)$ & 0.009 & $2.83(1.24-6.48)$ & 0.014 \\
\hline None & $60(50)$ & $60(50)$ & $2.5(1.28-4.82)$ & 0.008 & $2.64(1.34-5.19)$ & 0.005 \\
\hline \multicolumn{7}{|l|}{ Eating at restaurant } \\
\hline Yes & 45 (35.2) & $83(64.8)$ & $0.38(0.22-0.65)$ & 0.000 & $0.43(0.23-0.78)$ & 0.006 \\
\hline No & $56(58.9)$ & $39(41.1)$ & 1 & & 1 & \\
\hline
\end{tabular}

COR crude odds ratio, $\mathrm{Cl}$ confidence interval, AOR Adjusted odds ratio, 1 (referent)

Our study revealed that 'eating out' (eating in a restaurant regularly) was found to be protective for protozoa infection. For instance, the odds of acquiring protozoan infection was 0.43 times higher among those who regularly eat at a restaurant than those who cook and consume at their homes. It is supported by findings elsewhere that home is the location associated with significant foodborne illness risk. Home is the place to prepare most of the food we consume, thereby increasing the possibility of food mishandling [44]. Similarly, people in groups are known to be at risk of foodborne infections. For instance the immunocompromised, young infants and pregnant women live together thereby exacerbating the transmission of foodborne pathogens [45]. Furthermore, most consumers do not perceive themselves or someone in their families to be susceptible to foodborne illness [46], or do not follow all recommended food safety practices [47], and consequently they do not take sufficient precautions.

The present study also showed that the magnitude of protozoan infection was higher among participants whose water for drinking and cooking was collected from unprotected sources such as rivers. This was in agreement with the report in Cote d'Ivoire [48]. This might be an indication for the incomplete separation of human and animal waste with water sources that are used for drinking in the area [49]. In addition, the resistant cysts of the parasites for routine chlorination might have contributed for the relatively higher infection rates among those who used protected water sources as well.

\section{Conclusion}

Foodborne intestinal protozoa are of public health concern in the study area. Using vinegar as a decontaminant 
to eat fruits and vegetables was not protective of protozoa infections. Eating at a restaurant in a regular basis on the other hand was associated with lower odds of infection of foodborne protozoa parasites. Heath education should be given on handling of food at home and safe potable water should be provided to the society to interrupt the transmission of foodborne protozoan parasitic infections. Household latrines should also be built far from kitchens.

\section{Limitation of the study}

We were unable to identify the species of Cryptosporidium due to lack of molecular techniques. Other possible causes of diarrhea such as bacteria and/or viruses were not also illustrated.

\section{Abbreviations}

Cl: Confidence interval; CSA: Central Statistical Agency; OR: Odds ratio; SPSS: Statistical Product and Service Solutions

\section{Acknowledgments}

We are thankful to laboratory personnel and clinicians at the selected health facilities and study participants for their willingness of participation. We also thank Mekelle University for financial support.

\section{Funding}

The research project was funded by Mekelle University.

\section{Availability of data and materials}

To generate findings of this particular study, data were collected and analyzed based on the stated methods and materials. All the data were incorporated in the manuscript and no supplementary files accompanied the submission. The original data supporting this finding will be available at any time upon request.

\section{Authors' contributions}

BB designed the study, analyzed data \& drafted manuscript; GB participated in the design of the study, data analysis and revision of the manuscript; SB participated in the design of the study, data analysis and revision of the manuscript, MA designed the study, analyzed data and wrote and revised the manuscript. All authors read and approved the final manuscript.

\section{Ethics approval and consent to participate}

Ethical approval was sought from Mekelle University, College of Health Sciences institutional review board (IRB) and was granted accordingly with the reference number (CHS/MT 56/2016).

Written consents were collected from the study participants. Parents of children of under 18 years old were informed of their children's participation and gave informed written consent for their children to participate. Assents were also collected from children. Participants positive for protozoa parasites were treated with anti-protozoal agents.

\section{Consent for publication}

Individual data such as images and videos did not accompany this particular manuscript and hence consent for publication is not applicable.

\section{Competing interests}

The authors declare that they have no competing interests.

\section{Publisher's Note}

Springer Nature remains neutral with regard to jurisdictional claims in published maps and institutional affiliations.

\section{Author details}

'Department of Bio-Medical Laboratory Science, College of Health Science, Adigrat University, Adigrat, Ethiopia. ${ }^{2}$ Department of Medical Parasitology and Entomology, Institute of Biomedical Sciences, College of Health Science,
Mekelle University, Mekelle, Ethiopia. ${ }^{3}$ Department of Medical Microbiology, Immunology and Parasitology, Bahir Dar University, Mekelle, Ethiopia. ${ }^{4}$ Department of Microbiology, Immunology and Parasitology, Bahir Dar University, PO Box 79, Bahir Dar, Ethiopia.

Received: 15 January 2018 Accepted: 24 February 2018

Published online: 02 March 2018

\section{References}

1. Cama VA, Mathison BA. Infections by intestinal coccidia and Giardia duodenalis. Clin Lab Med. 2015;35(2):423-44.

2. Torgerson PR, de Silva NR, Fevre EM. The global burden of foodborne parasitic diseases: an update. Trends Parasitol. 2014;30(1):20-6.

3. Baldursson S, Karanis P. Waterborne transmission of protozoan parasites: a review of worldwide outbreaks. Water Res. 2011:45(20):6603-14.

4. Thompson RCA, Ash A. Molecular epidemiology of Giardia and Cryptosporidium infections. Infect Genet Evol. 2016;40:315-23.

5. Putignani L and Menichella D. Global Distribution, public health and clinical impact of the protozoan pathogen, Cryptosporidium. Interdiscip Perspect Infect Dis. 2010; https://doi.org/10.1155/2010/753512.

6. Cheesbrough M. District Laboratory Practice in Tropical Countries, Part 1. 2nd ed. New York: Cambridge University Press; 2009.

7. Kalyoussef S, Goldman D. Giardiasis and cryptosporidiosis. Pediatr Review. 2010;31(2):81.

8. Center for Disease Control. Cryptosporidiosis and Giardiasis SurveillanceUnited States, 2011-2012. MMWR Morbidity and Mortality Weekly Report 2015;64(3):2-28

9. Wegayehu T, Adamu H, Petros B. Prevalence of giardia duodenalis and cryptosporidium species infections among children and cattle in north Shewa zone, Ethiopia. BMC Infect Dis. 2013;13:419.

10. Taye $S$, Abdulkerim A. Prevalence of intestinal parasitic infections among patients with diarrhea at Bereka medical center, Southeast Ethiopia: a retrospective study. Fam Med Med Sci Res. 2014;3:131.

11. Leenstra T, Phillips-Howard PA, Kariuki SK, Hawley WA, Alaii JA, Rosen $\mathrm{DH}$, et al. Permethrin-treated bed nets in the prevention of malaria and anemia in adolescent schoolgirls in western Kenya. Am J Trop Med Hyg. 2003;68:86-93.

12. Crookston BT, Alder SC, Boakye I, Merrill RM, Amuasi JH, Porucznik CA, et al. Exploring the relationship between chronic undernutrition and asymptomatic malaria in Ghanaian children. Malar J. 2010;9:39.

13. Erko B, Teferi G, Medhin G. Reinfection of school children with schistosomiasis mansoni in the Fincha valley western Ethiopia. Ethiop J Health Dev. 2004;11:269-73.

14. Erko B, Medhin G. Human helminthiasis in Wondo genet, southern Ethiopia, with emphasis on geohelminthiasis. Ethiop Med J. 2003;41(4):333-44.

15. Yami A, Mamo Y, Kebede S. Prevalence and predictors of intestinal helminthiasis among school rechildren in Jimma zone; a cross-sectional study. Ethiopian J Health Sci. 2011;21:167-74.

16. Girum $T$. The prevalence of intestinal helminthic infections and associated risk factors among school children in Babile town, eastern Ethiopia. Ethiop J Health Dev. 2005;19:140-7.

17. Legesse M, Erko B. Prevalence of intestinal parasite among school children in a rural area close to the southeast of Lake Langano, Ethiopia. Ethiopian J Health Dev. 2004;18(2):116-20.

18. Mengistu $L$, Berhanu E. Prevalence of intestinal parasites among schoolchildren in a rural area close to the southeast of Lake Langano, Ethiopia. Ethiop J Health Dev. 2004;18:116-20.

19. Merid Y, Hegazy M, Mekete G, Teklemariam S. Intestinal helminthic infection among children at Lake Awassa area, South Ethiopia. Ethiop J Health Dev. 2001;15:31-7

20. Hurry K, Kassu A, Mulu A, Worku N, Fetene T, et al. Intestinal iparasitosis and shigellosis among diarrheal patients in Gondar teaching hospital, Northwest Ethiopia. BMC Res Notes. 2011:4:47

21. Negase A. Prevalence of intestinal protozoan parasites among primary school children and drinking water sources in Gerbe Guracha Town, Kuyu woreda, north Shoa, Oromia, Ethiopia. http://hulirs.haramaya.edu.et/bitstream/handle/ 123456789/3264/Negase\%20Abera\%20\%20Final\%20thesis\%20Nov.\%202014. pdf?sequence $=1$ \&isAllowed $=y$.

22. Alexander KA, Herbein J, Zajac A. The occurrence of Cryptosporidium and Giardia infections among patients reporting diarrheal disease in Chobe district, Botswana. Adv Infect Dis. 2012;2:143-7. 
23. Sarkari B, Hosseini G, Motazedian MH, Fararoue M, Moshfe A, et al. Prevalence and risk factors of intestinal protozoan infections: a population-based study in rural areas of Boyer-Ahmad district, southwestern Iran. BMC Infect Dis. 2016;16:703.

24. Kiani H, Haghighi A, Rostami A, Azargashb E, Seyyed Tabaei SJ, et al. Prevalence, risk factors and symptoms associated to intestinal parasite infections among patients with gastrointestinal disorders in Nahavand western Iran. Rev Inst Med Trop Sao Paulo. 2016;58:42.

25. Samie A , Guerrant RL, Barrett L, Bessong PO, Igumbor E.O. Prevalence of intestinal parasitic and bacterial pathogens in diarrheal and non-diarrheal human stools from Vhembe district, South Africa. J Health Popul Nutr 2009; 27(6):739-745.

26. Osman M, El Safadi D, Cian A, Benamrouz S, Nourrisson C, et al. Prevalence and risk factors for intestinal protozoan infections with cryptosporidium, giardia, Blastocystis and Dientamoeba among school children in Tripoli, Lebanon. PLoS Negl Trop Dis. 2016;10(3):e0004496. https://doi.org/10.1371/ journal.pntd.0004496.

27. Hussein TK. Prevalence and related risk factors for Giardia lamblia infection among children with acute diarrhea in thi-qar, southern Iraq. TQM J. 2010; 4(4):68-74.

28. Endeshaw T, Mohammed H, Woldemichael T. Cryptosporidium parvum and other intestinal parasites among diarrheal patients referred to EHNRI in Ethiopia. Ethiop Med J. 2004;42:195-8.

29. Ramos JM, Valero NR, Tisiano G, Fano H, Yohannes T. Different profile of intestinal protozoa and helminthic infectious among patients with diarrhoea according to age attending a rural hospital in southern Ethiopia. Trop Biomed. 2014;31(2):392-7.

30. Asrat A, Tewodros D, Alemayehu W. Prevalence and risk factors of IPS among Delgi school children, northern Gonder, Ethiopia. J Parasitol Vector Biol. 2011;3(5):75-81.

31. Zaglool DAM, Khodari YAW, Gazzaz ZJ, Dhafar KO, Shaker HAS, Farook MV. Prevalence of intestinal parasites among patients of al-Noor specialist hospital, Makkah, Saudi Arabia. Oman Med J. 2011;26(3):182-5.

32. Jamaiah I, Rohela M. Prevalence of intestinal parasites among members of the public in Kuala Lumpur, Malaysia. Southeast Asian J Trop Med Public Health. 2005;36:68-71.

33. Peruzzi S, Gorrini C, Piccolo G, Calderaro A, Dettori G, et al. Prevalence of intestinal parasites in the area of Parma. Acta Biomed. 2006;77:147-51.

34. Prasert R, Pitak W, Nipon T. Factors associated with intestinal parasites among households in Ratchaburi province, Thai-Myanmar border area. J Trop Med Parasitol. 2008;31:85-94.

35. Natividad FF, Buerano CC, Lago CB, Maua CA, Uzman BB, et al. Prevalence rates of Giardia and Cryptosporidium among diarrheic patients in the Philippines. Southeast Asian J Trop Med Public Health. 2008;39(6):993.

36. Daniels ME, Shrivastava A, Smith WA, Sahu P, Marion and Jenkins MW. Cryptosporidium and Giardia in humans, domestic animals, and village water sources in rural India. Am J Trop Med Hyg 2015; 93(3): 596-600.

37. Liu H, Shen Y, Yin J, Yuan Z, Jiang Y, Xu Y, et al. Prevalence and genetic characterization of cryptosporidium, Enterocytozoon, giardia and Cyclospora in diarrheal outpatients in China. BMC Infect Dis. 2014;14:25

38. Sadjjadi SM, Rostami J, Azadbakht M. Giardiacidal activity of lemon juice, vinifer and vinegar on Giardia intestinalis cysts. Southeast Asian J Trop Med Public Health. 2006;37(3):24-7.

39. Al-Saeed AT, Issa SH. Frequency of Giardia lamblia among children in Dohuk, northern Iraq. East Mediterr Health J. 2006;12(5):555-61.

40. Babatunde, Kola S, Fadeyi, Abayomi, Akanbi II et al. Cyclosporiasis and other intestinal parasitoses in association with diarrhoea in Ilorin, Nigeria. Afr J Microbiol Res. 2013;7(21):2613-2617.

41. Hawash Y, Dorgham LS, Al-Hazmi AS, Al-Ghamdi MS. Prevalence of Cryptosporidium-associated diarrhea in a high altitude-community of Saudi Arabia detected by conventional and molecular methods. Korean J Parasitol. 2014;52(5):479-85.

42. Costa AO, Thomaz-Soccol V, Paulino RC, de Castro EA. Effect of vinegar on the viability of Giardia duodenalis cysts. Int J Food Microbiol. 2009;128:510-2.

43. Hezarjaribi HZ, Elmi T, Dayer MS, Gholami S, Fakhar M, Akbariqomi M, et al A systematic review of the effects of Iranian pharmaceutical plant extracts on Giardia lamblia. Asian Pac J Trop Dis. 2015;5(12):925-9.

44. Carlson A, Kinsey J, Nadav C. Consumers' retail source of food: a cluster analysis. Fam Econ Nutr Rev. 2002;14:11-20.
45. Kunisaki K, Janoff E. Influenza in immunosuppressed populations: a review of infection frequency, morbidity, mortality, and vaccine response. Lancet Infect Dis. 2009;9:493-504.

46. Buffer J, Kendall P, Medeiros LC, Schroeder M, Sofos J. Nutrition and dietitians differ in food safety information provided to highly susceptible clients. J Nutr Educ Behav. 2013:45:102-8.

47. Jevsnik M, Hoyer S, Raspor P. Food safety knowledge and practices among pregnant and non-pregnant women in Slovenia. Food Control. 2008;19: 526-34.

48. Koffi M, N'Djeti M, Konan T, Dje Y. Molecular characterization of intestinal protozoan parasites from children facing diarrheal disease and associated risk factors in Yamoussoukro, cote d'Ivoire. Afr J Environ Sci Technol. 2014; 8(3):178-84.

49. Alemu M, Kinfe B, Tadesse D, Mulu W, Hailu T, Yizengaw E. Intestinal parasitosis and anaemia among patients in a health center, North Ethiopia. BMC Res Notes. 2017;10:632

\section{Submit your next manuscript to BioMed Central and we will help you at every step:}

- We accept pre-submission inquiries

- Our selector tool helps you to find the most relevant journal

- We provide round the clock customer support

- Convenient online submission

- Thorough peer review

- Inclusion in PubMed and all major indexing services

- Maximum visibility for your research

Submit your manuscript at www.biomedcentral.com/submit 